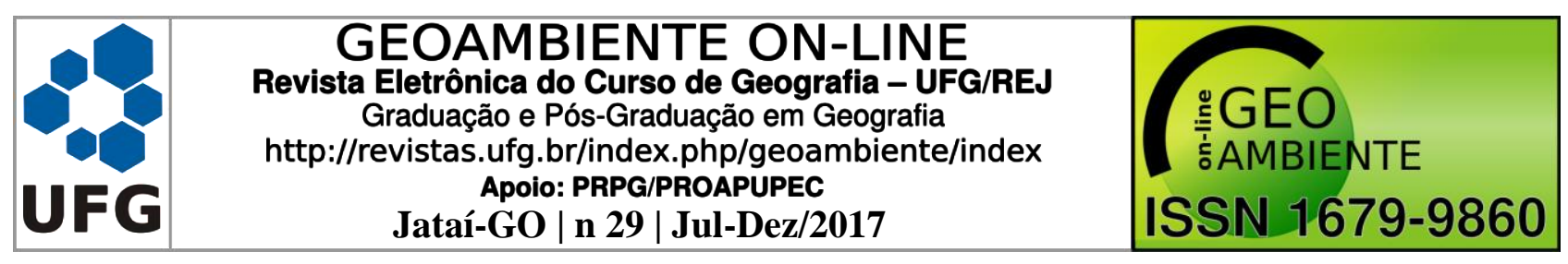

\title{
FRAGMENTAÇÃO DA PAISAGEM NO MUNICÍPIO DE FÁTIMA, TO - BRASIL
}

Telma Maria do Vale', Ricardo Ribeiro Dias ${ }^{2}$.

(1 - Universidade Federal do Tocantins, Engenheira Ambiental - UFT - Palmas. telma09@uft.edu.br, 2 - Universidade Federal do Tocantins, Docente do curso de Engenharia Ambiental - Palmas. ricdias@uft.edu.br )

Resumo: Buscou-se avaliar a fragmentação dos ambientes de vegetação primitiva, com a indicação de um possível corredor ecológico dentro do município de Fátima. Analisaram-se os remanescentes de Floresta Estacional Semidecidual Aluvial, Savana Arborizada/Floresta Estacional Semidecidual Submontana, Savana Arborizada e Savana Parque. Utilizaram-se os índices: área, borda, área central, forma e dimensão fractal média. Constatou-se que a Savana Arborizada apresenta os principais fragmentos para conservação por tamanho, maior regularidade das formas e bom grau de conservação de áreas interior. Destacam-se dois fragmentos de grande extensão (Bacia do Ribeirão Enseada), indicados para conservação ambiental e as suas conectividades podem ser estabelecidas por fragmentos de Floresta Estacional Semidecidual. Os resultados da análise da fragmentação, também mostram que Fátima tem pouca área para implantar um programa de conservação ambiental por meio de áreas protegidas, sendo necessária uma ação imediata do poder público municipal para a preservação da vegetação na parte leste da Bacia Hidrográfica do Ribeirão Enseada, nos contrafortes da Serra das Cordilheiras. Os fragmentos das outras formações florestais desempenham papel importante para a conectividade dos maiores fragmentos.

Palavras-chave: Paisagem. Fragmentação. Conectividade.

\section{FRAGMENTATION OF THE LANDSCAPE IN THE MUNICIPALITY OF FÁTIMA, TOCANTINS STATE, BRAZIL}

Abstract: The objective of this study was to evaluate the fragmentation of environments with native vegetation and indicate a possible ecological corridor within the municipality of

\footnotetext{
Artigo recebido para publicação em 07 de Julho de 2016

Artigo aprovado para publicação em 04 de Dezembro de 2017
} 


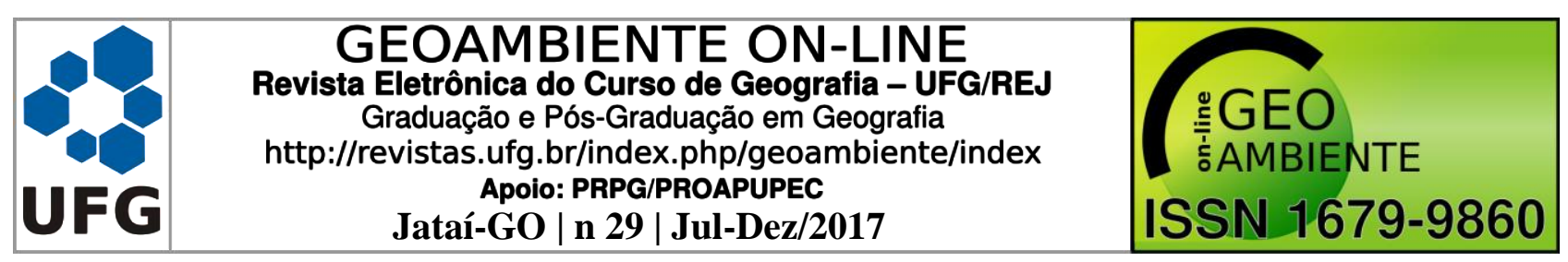

Fátima, Tocantins state, Brazil. Remnants of Alluvial Semi-Deciduous Seasonal Forest, Tree-

Savannah/Semi-Deciduous Submontane Seasonal Forest, Tree-Savannah, and ParqueSavannah were analyzed. The indexes area, border, central area, shape, and average fractal dimension were used. The Tree-Savannah presents the main fragments for conservation due to its size, greater shape regularity and degree of conservation of interior areas. Two fragments of great extension in the Ribeirão Enseada Basin are indicated for environmental conservation, with connections that can be established by fragments of Semi-Deciduous Seasonal Forest. The results of the fragmentation analysis show that Fatima has little area for the implementation of an environmental conservation program through protected areas, indicating the need of action by municipal public authorities in preserving vegetation in the eastern part of the Ribeirão Enseada Basin, in the foothills of the Serra das Cordilheiras mountains. The fragments of other forest formations play an important role in connecting larger fragments.

Keywords: Landscape. Fragmentation. Connectivity.

\section{FRAGMENTACIÓN DEL PAISAJE EN EL MUNICIPIO DE FÁTIMA, ESTADO DE TOCANTINS, BRASIL}

Resumen: El objetivo de este estudio fue evaluar la fragmentación de los ambientes de vegetación nativa e indicar un posible corredor ecológico dentro del municipio de Fátima, en lo Estado de Tocantins, Brasil. Remanentes del Bosque Estacional Semidecidual Aluvial, Sabana Arbolada/Bosque Estacional Semidecidual Submontano, Sabana Arbolada y Sabana Parque fueron analizados. Se utilizaron los índices de área, borde, área central, forma y dimensión fractal media. La Sabana Arbolada presenta los principales fragmentos para conservación debido a su tamaño, mayor regularidad de formas y grado de conservación de áreas interiores. Dos fragmentos de gran extensión en la Cuenca del Ribeirão Enseada son indicados para conservación ambiental, con conexiones que pueden ser establecidas por fragmentos de Bosque Estacional Semidecidual. Los resultados del análisis de la fragmentación muestran que Fátima tiene poca área para la implementación de un programa de conservación ambiental a través de áreas protegidas, siendo necesaria la acción del poder público municipal para la preservación de la vegetación en la parte este de la Cuenca del Ribeirão Enseada, en los contrafuertes de la Serra das Cordilheiras. Los fragmentos de las 


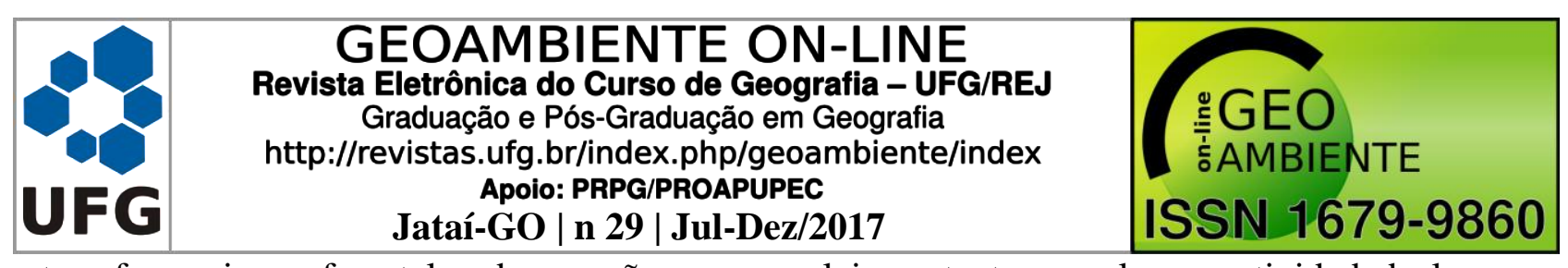

otras formaciones forestales desempeñan un papel importante para la conectividad de los mayores fragmentos.

Palabras-clave: Paisaje. Fragmentación. Conectividad.

\section{INTRODUÇÃO}

Após a Mata Atlântica, o Cerrado é o bioma que mais sofre antropização, compreendendo desmatamento para atividades extrativistas, madeireira e produção de carvão, assim como para atividades agropecuárias.

O estado do Tocantins tem $90 \%$ de sua área no Cerrado, sendo bastante antropizada as terras entre os rios Tocantins e Araguaia. O Cerrado tem sido amplamente explorado, devido principalmente à expansão agrícola, acarretando impactos ambientais e sociais positivos, e também negativos. Dentre os aspectos negativos, destaca-se a fragmentação das fitofisionomias do cerrado, formando ilhas ou manchas de vegetação nativa que acabam passando por mudanças físicas e biológicas, especialmente a redução de habitats da fauna. Todavia, ainda são poucos os estudos de paisagem no território tocantinense que avaliam a fragmentação dos cerrados em função do uso e ocupação da terra.

A economia tocantinense baseia-se principalmente em comércio, agricultura e pecuária, não sendo diferente no município de Fátima. O Tocantins é produtor de arroz, milho e soja, e existe uma tendência de aumento de terras a serem incorporadas para a produção de soja. Isto traz um crescimento do desmatamento e da fragmentação da paisagem natural, acarretando em perda de biodiversidade.

Estudos que avaliam a fragmentação do cerrado em função do uso e ocupação da terra são de relevante atenção em ampla escala, desde a regional até a nacional. Eles podem subsidiar a criação de unidades de conservação e o estabelecimento de corredores ecológicos, sendo, portanto, indispensáveis como ferramenta no planejamento e na gestão ambiental.

Neste contexto, escolheu-se o município de Fátima, na região central do Tocantins, com a expansão da sojicultora com o objetivo avaliar a fragmentação dos ambientes de vegetação primitiva, com a indicação de um possível corredor ecológico dentro do município de Fátima.

\section{Referencial Teórico}




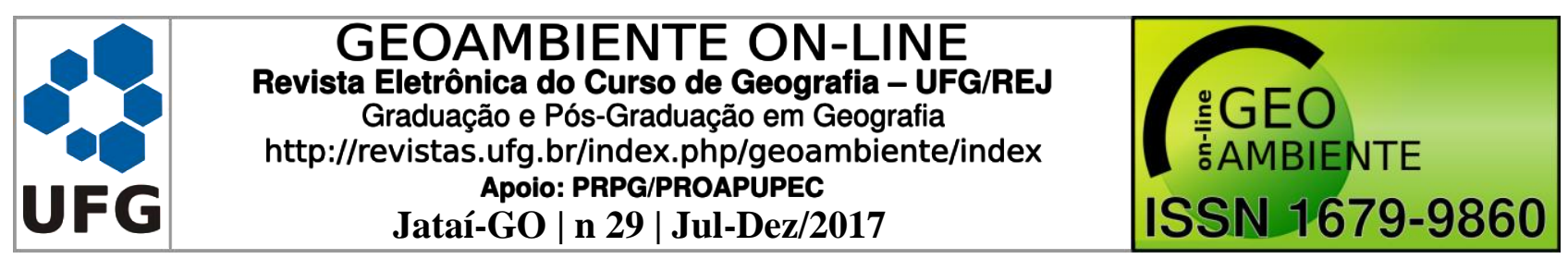

O bioma cerrado é considerado uma das áreas prioritárias de preservação para a conservação da biodiversidade, todavia, este tem sido o bioma com maior conversão para áreas de pastagens e culturas agrícolas (SILVA; MELLO; STEINKE, 2012).

Com a preocupação da perda de biodiversidade e outros impactos da degradação de florestas tropicais, aumentou o desenvolvimento de estudos sobre os processos envolvidos na dinâmica do desflorestamento (FARINACI; BATISTELLA, 2012). Através do SIG (Sistema de Informações Geográficas) torna-se possível visualizar rapidamente as áreas degradadas, bem como praticar as devidas ações de recuperação de áreas de vegetação (LEAL; TODT; THUM, 2013). Segundo Bohrer (2000), o uso de métodos de paisagem e integração dos dados sobre diferentes atributos em SIG pode melhorar consideravelmente a utilização de dados provenientes de levantamentos de vegetação no planejamento do uso da terra.

A caracterização da estrutura da paisagem visa desvendar as origens ou os mecanismos causais das texturas ou padrões, para com isso desenvolver modelos de paisagem que permitam verificar os hotspots (prioritário de conservação) evitando assim os firespots intensamente degradados (REMPEL, 2009). Atualmente os processos de fragmentação representam uma das maiores preocupações no âmbito da conservação da biodiversidade, já que a heterogeneidade dos fragmentos afeta a dinâmica e o estabelecimento de espécies vegetais e animais (CRUZ; MADUREIRA; MARQUES, 2013).

Estudos que avaliam entender os padrões ecológicos da paisagem são fundamentais para estabelecer diretrizes que visem à compatibilização do uso múltiplo dos recursos naturais com demais políticas setoriais que, intervenham no contexto de desenvolvimento sustentável aplicado aos padrões ecológicos da área, como cita Monteiro; Martins (2013).

\section{Índice de Área}

Cullen, Rudran e Padua (2006) apontam que, a área é interpretada como a medida da estrutura da paisagem mais próxima é mais difundida e, por isso, talvez a mais importante. Sendo a área total de uma classe é a soma de todas as áreas de manchas de uma determinada classe numa paisagem. A posição central do atributo espacial "área" deve ser considerada inteiramente relacionada à sua grande importância na ecologia.

Índices de avaliação da fragmentação da paisagem

Os índices analisados neste estudo estão conforme a tabela 1 e descritos a seguir são: 


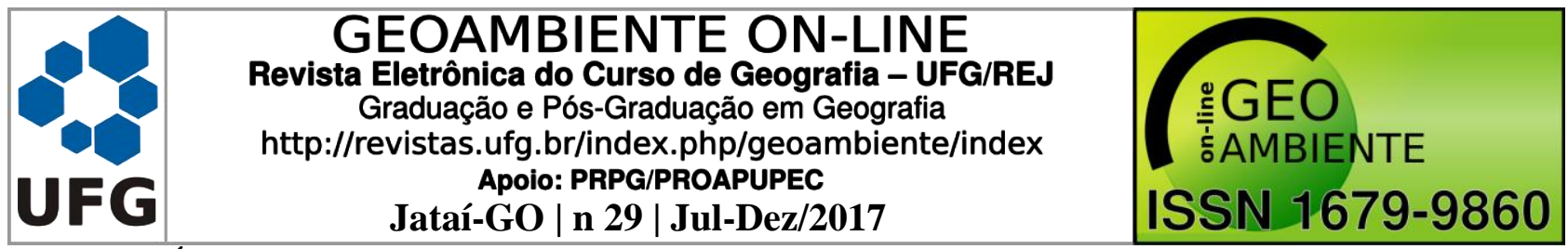

Tabela 1. Índices de ecologia da paisagem para os fragmentos de vegetação.

\begin{tabular}{|c|c|c|c|}
\hline Índice & Sigla & Métrica e unidade & Descrição \\
\hline Área & $\mathrm{CA}$ & Área da classe (ha) & $\begin{array}{l}\text { Soma das áreas de todas as manchas pertencentes à } \\
\text { determinada classe. }\end{array}$ \\
\hline $\begin{array}{l}\text { Área } \\
\text { Central }\end{array}$ & TCA & Área central Total (ha) & $\begin{array}{l}\text { Classe ocupada com área central, após a retirada da } \\
\text { faixa referente ao efeito de borda. }\end{array}$ \\
\hline Bordas & TE & Total de bordas (m) & $\begin{array}{l}\text { Soma dos perímetros de todas as bordas dentro da } \\
\text { classe }\end{array}$ \\
\hline $\begin{array}{l}\text { Densidade } \\
\text { e } \\
\text { Tamanho }\end{array}$ & NUMP & $\begin{array}{l}\text { Número de manchas } \\
\quad \text { (adimensional) }\end{array}$ & $\begin{array}{l}\text { Número total de fragmentos dentro de uma mesma } \\
\text { classe. }\end{array}$ \\
\hline Forma & MPFD & $\begin{array}{l}\text { Dimensão fractal da mancha } \\
\text { média (adimensional) }\end{array}$ & $\begin{array}{l}\text { Medida onde os valores se aproximam de um para } \\
\text { formas com perímetros simples e para dois quando } \\
\text { as formas forem mais complexas }\end{array}$ \\
\hline
\end{tabular}

Fonte: Adaptado de McGarigal; Marks (1994) e McGarigal; Marks (1995).

\section{Índice de Borda}

Os índices de borda usualmente são considerados como representantes da configuração da paisagem. Segundo Missio et al. (2004), o efeito de borda é um dado importante na análise da vulnerabilidade dos fragmentos de mata, considerando que, quanto maior a distância entre as bordas e o interior do fragmento, maior será a proteção das espécies do interior dessas áreas a ameaças externas. Em seu estudo Sarcinelli (2006), aponta que ao observar cenários sem a restrição de borda, ocorreram fragmentos mais alongados e de pouca área central, do que aqueles de alocação restrita a borda.

\section{Índice de Densidade e Tamanho}

Volotão (1998) cita que os índices de densidade e tamanho caracterizam os fragmentos de acordo com número de fragmentos, tamanho médio, densidade, variação, e entre outras atribuições. Dando ordem de acordo com a fragmentação, a heterogeneidade dos fragmentos e demais interesses observados e relacionados aos fragmentos na paisagem.

\section{Índice de Forma}

A forma é útil na análise da vulnerabilidade dos fragmentos a perturbações, indicando os efeitos de borda. Esta importante análise em estudos da dinâmica e estrutura dos 


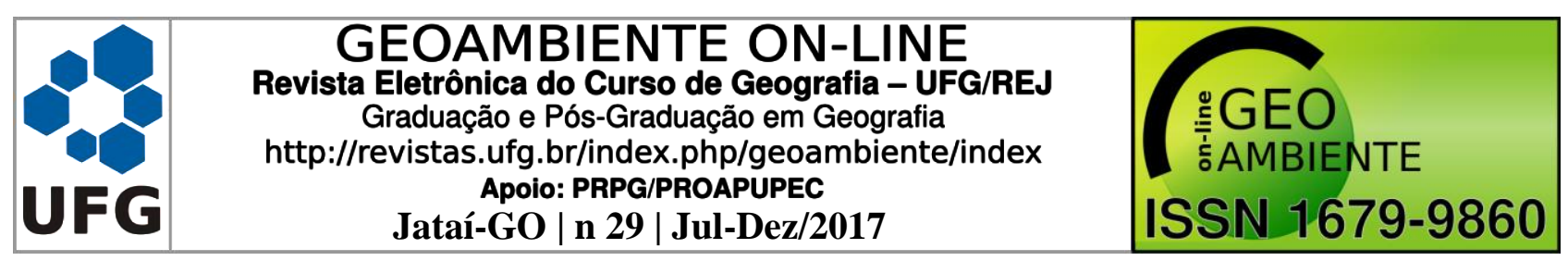

fragmentos florestais possibilita indicar o nível de proteção de seu interior em relacionado a efeitos de borda (OLIVEIRA, 2011). Segundo Viana e Pinheiro (1998), a forma é a relação entre área de um fragmento florestal e o seu perímetro.

\section{Índice de Área Central}

Segundo Laurence (1991), a área central estima a área total do habitat preservada dentro dos fragmentos, excetuando então as bordas. Esta área central é a área dentro de um fragmento separada da borda por uma distância pré-definida. Para Volotão (1998), esta medida é de grande valia (do ponto de vista de previsão) na observância da qualidade de habitats, por especialistas de áreas interiores do que a área dos fragmentos.

Pereira et al. (2001), para o estudo dos efeitos de borda considerando o desflorestamento tropical em uma área amazônica, consideraram um efeito de borda de 1000 metros. Borges et al. (2004) em ambientes de formação florestal, savânicas e contato, consideraram um efeito de borda de 50 metros. Santos e Machado (2015), em uma área de cerrado, consideraram também para efeito de borda, o valor de 50 metros, sem levar em conta nenhuma espécie alvo ou processo específico.

\section{MATERIAIS E MÉTODOS}

\subsection{Descrição da área de estudo}

O município de Fátima localiza-se na região central do Tocantins entre Latitude Sul de $10^{\circ} 45^{\prime} 42^{\prime}$ Sul, e longitudes Oeste de $48^{\circ} 54^{\prime}$ 3" (Figura 1). Com área de 383 km², o município fica a $126 \mathrm{~km}$ distante de Palmas - capital do Estado, e tem uma população 3.989 habitantes (IBGE, 2014). Os acessos à cidade são pelas vias, BR-153, TO-362 e TO-255.

O município de Fátima possui, de acordo com a classificação climática de KöppenGeiger, um clima tropical com um período mais prolongado de seca. Segundo a Seplan (2012), a precipitação média anual está em torno de $1.800 \mathrm{~mm}$, ocorrendo apenas durante o verão.

Fátima possui hidrografia composta por cursos d'água pertencentes às bacias dos rios Crixás (ribeirões Enseada e Feliciano) e Mangues, que abastecem o Rio Tocantins, e da bacia do Rio Formoso, que é afluente do Rio Javaés (Bacia do Rio Araguaia). 


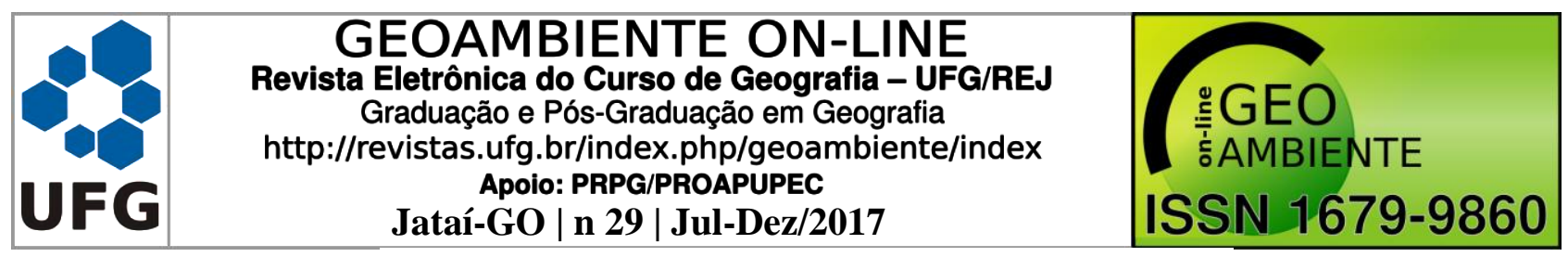

Figura 1. Mapa de localização do município de Fátima.

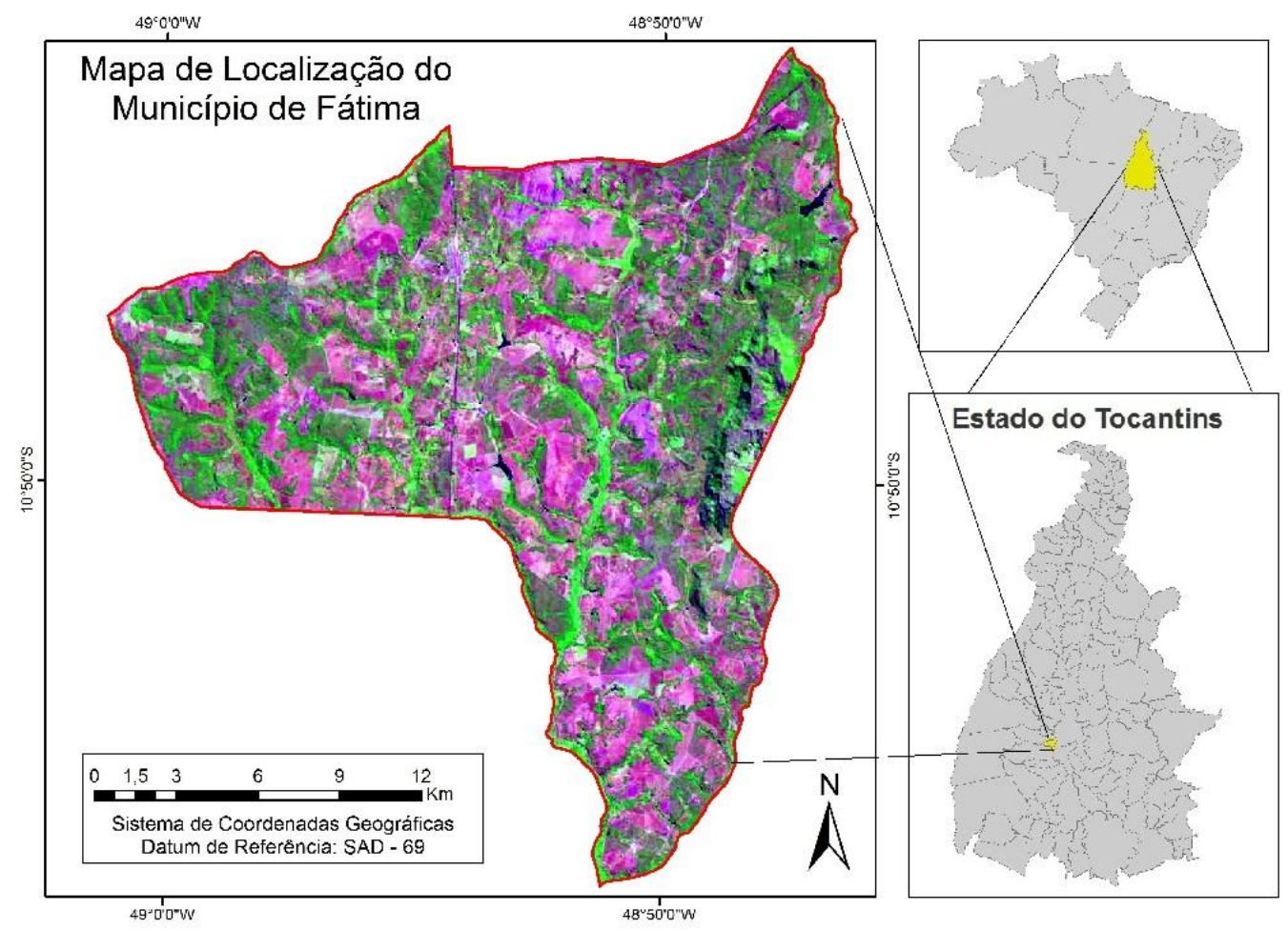

Organização: autores

A vegetação existente na área de estudo é de cerrado (IBGE, 2014). Os fragmentos de vegetação nativa na região de Fátima sofrem a pressão das áreas agrícolas e pastagens existentes, sendo perceptível em larga escala, o aumento das áreas cultivadas com grãos.

Pelo mapeamento de cobertura e uso da terra realizado por Andrade (2016), observaram-se que o município possui os seguintes tipos de formações vegetais nativas também mapeados por Seplan (2013):

\section{Floresta Estacional Semidecidual Aluvial}

Formação que tem contato com as formações de cerrado, apresentando vegetação arbórea de médio a grande porte, com troncos retos e eventualmente inclinados. Com submata mais ou menos limpa, poucos herbáceos, excetuado as espécies de pteridófitas e ciperáceas.

\section{Floresta Estacional Semidecidual Submontana}

Nesta formação encontram-se dispersas as maiores disjunções deste tipo de vegetação florestal decidual. Este tipo de formação está presente em pequena porção da região central. 


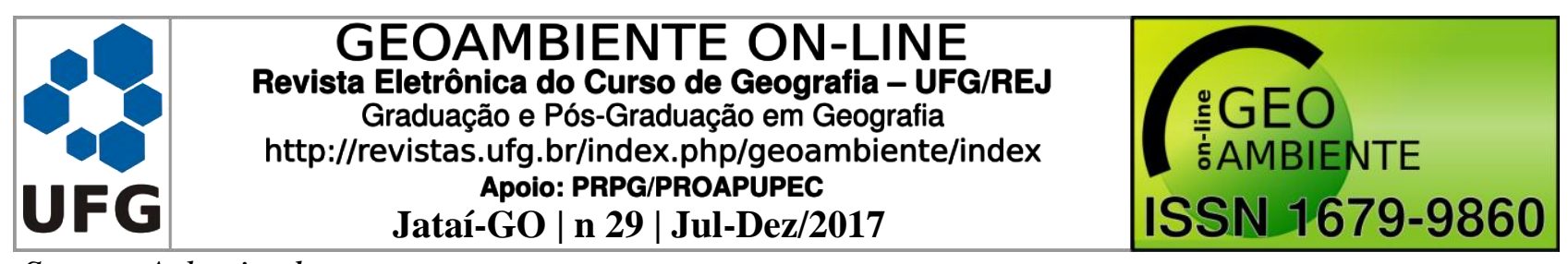

Savana Arborizada

Caracteriza-se por apresenta uma fisionomia com árvores baixas (até $8 \mathrm{~m}$ de altura) e hemicriptófitos contínuos, estando sujeita a queimadas anuais. Nessa formação, ocorre uma camada rasteira predominantemente graminosa e uma cobertura lenhosa.

Savana Parque

Formação essencialmente constituída por um estrato graminoide, integrado por hemicriptófitos e geófitos de florística natural e/ou antropizada, entremeada por nanofanerófitos isolados.

\subsection{Processamento e análise dos fragmentos}

Com o suporte do programa ArcGIS, foram realizadas análises e geração de mapas, cálculos de índice da paisagem. Utilizou-se o mapa de cobertura e uso da terra de Andrade (2016), elaborado a partir de imagens adquiridas no Instituto Nacional de Pesquisas Espaciais (INPE), bandas 4, 5 e 6 do sensor Operational Land Imager (OLI) do satélite Landsat 8 (órbita/ponto 222/68, de setembro de 2015). O mapa foi obtido por interpretação visual tendo como elementos de reconhecimento das classes de cobertura e uso da terra: tonalidade/cor, textura, padronização, localização, forma, sombra e tamanho.

Para a análise dos fragmentos confeccionou-se o mapa dos fragmentos florestais, sendo estes quantificados pela geração de índices da paisagem através do ArcGIS com a ferramenta Patch Analisty - que analisa a composição e/ou configuração da paisagem. Os índices analisados foram: área total da classe, área central, total de bordas, número de fragmentos, dimensão fractal média dos fragmentos. Para obter os dados foi utilizado um buffer com distância de 50 metros da borda, sendo que a seleção da largura de borda baseouse nos estudos de Pereira et al. (2001), Borges et al. (2004), Santos e Machado (2015).

\section{RESULTADOS E DISCUSSÃO}

\subsection{Mapeamento dos fragmentos}

O município de Fátima apresenta uma área dividida em 356 fragmentos de cobertura e uso da terra, conforme os dados de Andrade (2016). Estes fragmentos agrupados nas classes dos níveis I e II podem ser observados na Tabela 2 e na Figura 2. 


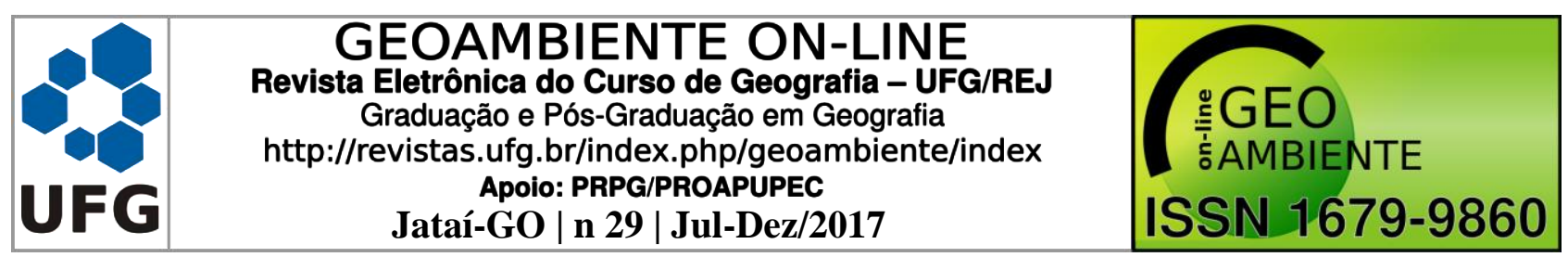

Tabela 2. Classes de cobertura e uso da terra e quantidade de fragmentos encontrados no município de Fátima.

\begin{tabular}{|c|c|c|c|c|c|}
\hline Classes - Nível I & Classes - Nível II & $\begin{array}{l}\text { Número de } \\
\text { Fragmentos }\end{array}$ & $\begin{array}{c}\text { Área } \\
\text { (ha) }\end{array}$ & $\%$ & $\begin{array}{c}\text { Tamanho Médio } \\
\text { dos Fragmentos } \\
\text { (ha) }\end{array}$ \\
\hline $\begin{array}{l}\text { Áreas Antrópicas } \\
\text { Não Agrícolas }\end{array}$ & Área Urbana & 1 & 214,55 & 0,56 & 214,55 \\
\hline $\begin{array}{l}\text { Áreas Antrópicas } \\
\text { Agrícolas }\end{array}$ & $\begin{array}{l}\text { Culturas Temporárias / } \\
\text { Pastagem } \\
\text { Savana }\end{array}$ & 88 & $19.259,20$ & 50,14 & 173,50 \\
\hline Áreas de Vegetação & $\begin{array}{l}\text { Arborizada/Floresta } \\
\text { Estacional Semidecidual } \\
\text { Submontana }\end{array}$ & 8 & 347,97 & 0,91 & 43,49 \\
\hline Nativa & $\begin{array}{l}\text { Savana Arborizada } \\
\text { Savana Parque }\end{array}$ & $\begin{array}{c}178 \\
8\end{array}$ & $\begin{array}{c}10.344,87 \\
819,22\end{array}$ & $\begin{array}{c}26,93 \\
2,13\end{array}$ & $\begin{array}{c}58,11 \\
102,40\end{array}$ \\
\hline & $\begin{array}{l}\text { Floresta Estacional } \\
\text { Semidecidual Aluvial }\end{array}$ & 66 & $7.341,47$ & 19,11 & 111,23 \\
\hline Água & $\begin{array}{l}\text { Águas Continentais } \\
\text { Total }\end{array}$ & $\begin{array}{c}7 \\
356\end{array}$ & $\begin{array}{c}80,42 \\
\mathbf{3 8 . 4 0 7 , 7 0} \\
\end{array}$ & $\begin{array}{c}0,21 \\
\mathbf{1 0 0 , 0 0}\end{array}$ & $\begin{array}{c}10,05 \\
-\end{array}$ \\
\hline
\end{tabular}

Fonte: Elaborada a partir de Andrade (2016).

Figura 2. Mapa de cobertura e uso da terra do município de Fátima - ano 2015

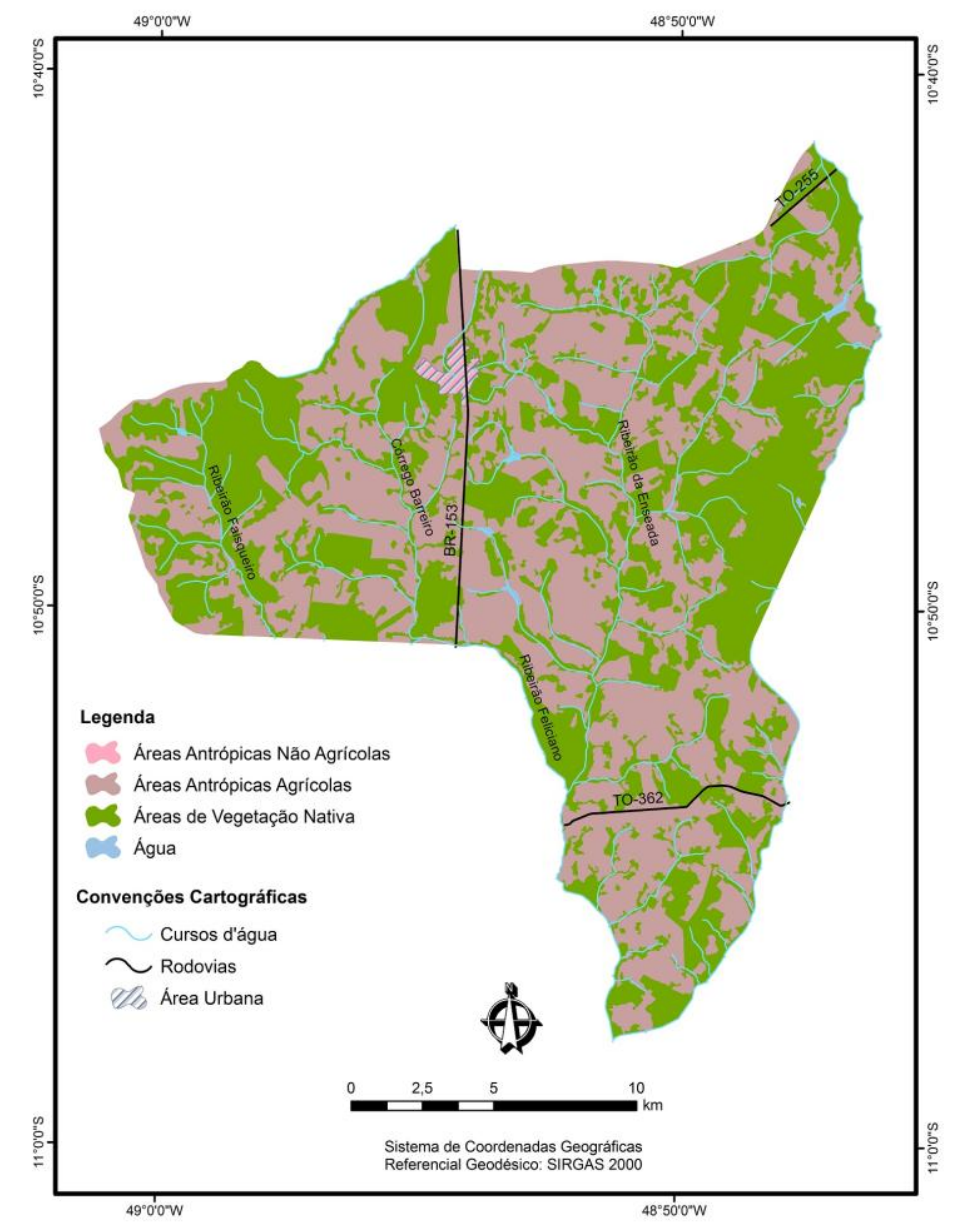

Fonte: Elaborado com base em Andrade (2016) 


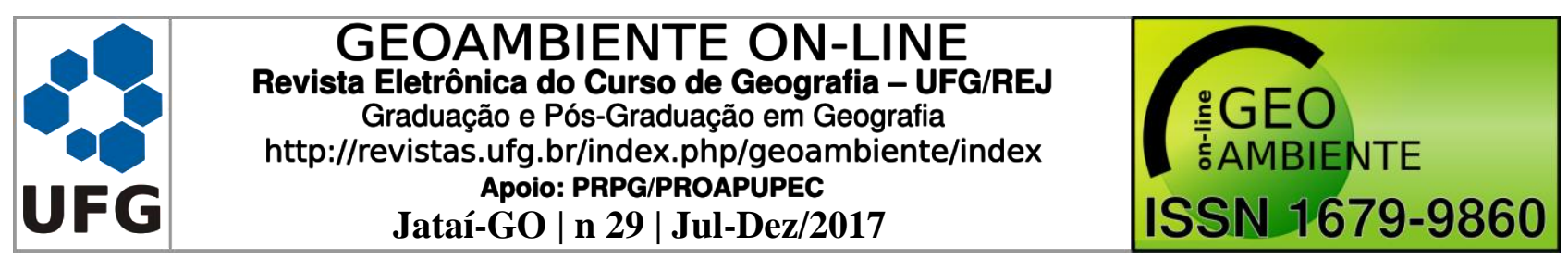

De acordo com a Tabela 2, em termos de área, a classe de maior extensão é a das Áreas Antrópicas Agrícolas, que compreendem 50,14\% das terras do município. Ela vem seguida da classe Áreas de Vegetação Nativa, que cobre 49,09\% de Fátima. As classes com menores expressões são Área urbana e Corpos d'água, respectivamente com 0,56 e 0,21\% da área total do município. Considerando o número de fragmentos, a classe Áreas de Vegetação Nativa mostra-se com a maior quantidade, chegando aos 260 fragmentos, cujo tamanho médio é de 70,91 ha.

As Áreas Antrópicas Agrícolas contêm 88 fragmentos (tamanho médio de 218,85 ha), ao passo que a de Água (101,48 ha) e de Áreas Antrópicas Não Agrícolas (214,55 ha), Juntas elas totalizam nove fragmentos.

Após gerar os índices de métricas de paisagem, pela ferramenta Patch Analisty dentro do ambiente ArcGIS (Tabela 3), observou-se que as Áreas de Vegetação Nativa possuem fragmentos de formas e tamanhos variados. Esses fragmentos totalizam $1.137 .417 \mathrm{~m}$ de bordas e uma dimensão fractal de 1,46. Valores semelhantes a estes foram encontrados no estudo de Pereira et al. (2012). Tais valores representam que os fragmentos mostram pouca complexidade em suas bordas, tendo ainda formas regulares, evidenciando o antropismo na área.

Tabela 3. Valores dos índices de métricas para toda a vegetação.

\begin{tabular}{ccccc}
\hline $\begin{array}{c}\text { Área total da } \\
\text { vegetação } \\
\text { nativa (ha) }\end{array}$ & $\begin{array}{c}\text { Número de } \\
\text { fragmentos }\end{array}$ & $\begin{array}{c}\text { Total de } \\
\text { bordas (m) }\end{array}$ & $\begin{array}{c}\text { Dimensão fractal do } \\
\text { fragmento médio } \\
(1 \text { a 2) }\end{array}$ & Área interior (ha) \\
\hline 188.535 .400 & 260 & 1.137 .417 & 1,46 & $13.688,15$ \\
\hline
\end{tabular}

A forma regular dos fragmentos das Áreas de Vegetação Nativa favorece a um menor efeito de borda e consequentemente menor afetação da biodiversidade do fragmento. A área interior desses fragmentos é de 13.688,15 ha, indicando que 27,40\% deles são constituídos por bordas (5.165,39 ha), o que resulta na quase manutenção de seus tamanhos originais, podendo levar a uma boa qualidade de habitats. No entanto, a maioria dos fragmentos está próximo a cursos d'água, sendo mais alongados e favorecendo a formação de corredores, caracterizando uma fragmentação ripária (PEREIRA et al., 2012).

A distribuição e classificação dos tamanhos dos fragmentos é uma estratégia importante no desenvolvimento do estudo e também da conservação da diversidade na vegetação natural. Neste trabalho foram encontrados 260 fragmentos de vegetação natural; 


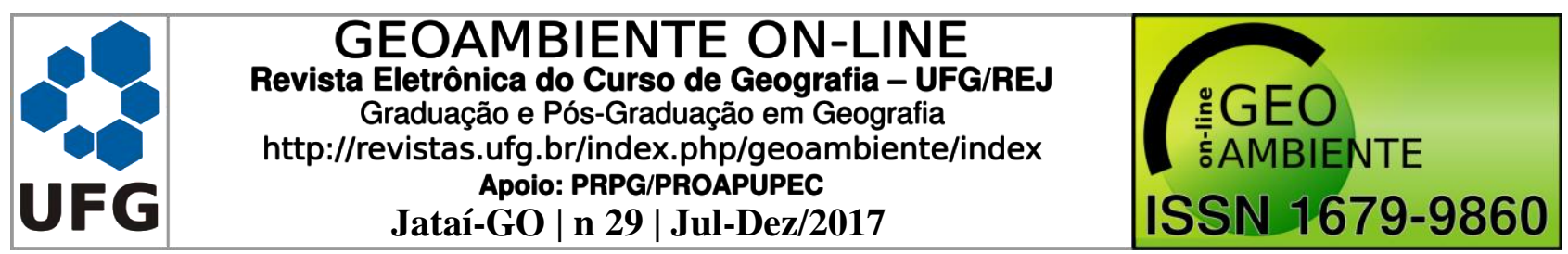

compostos por quatro tipos de formação florestal e divididos em quatro classes de tamanhos de fragmentos (Figura 3), a fim de atender a diversidade de vegetação e tamanhos destes elementos.

Figura 3. Mapa dos fragmentos de vegetação natural

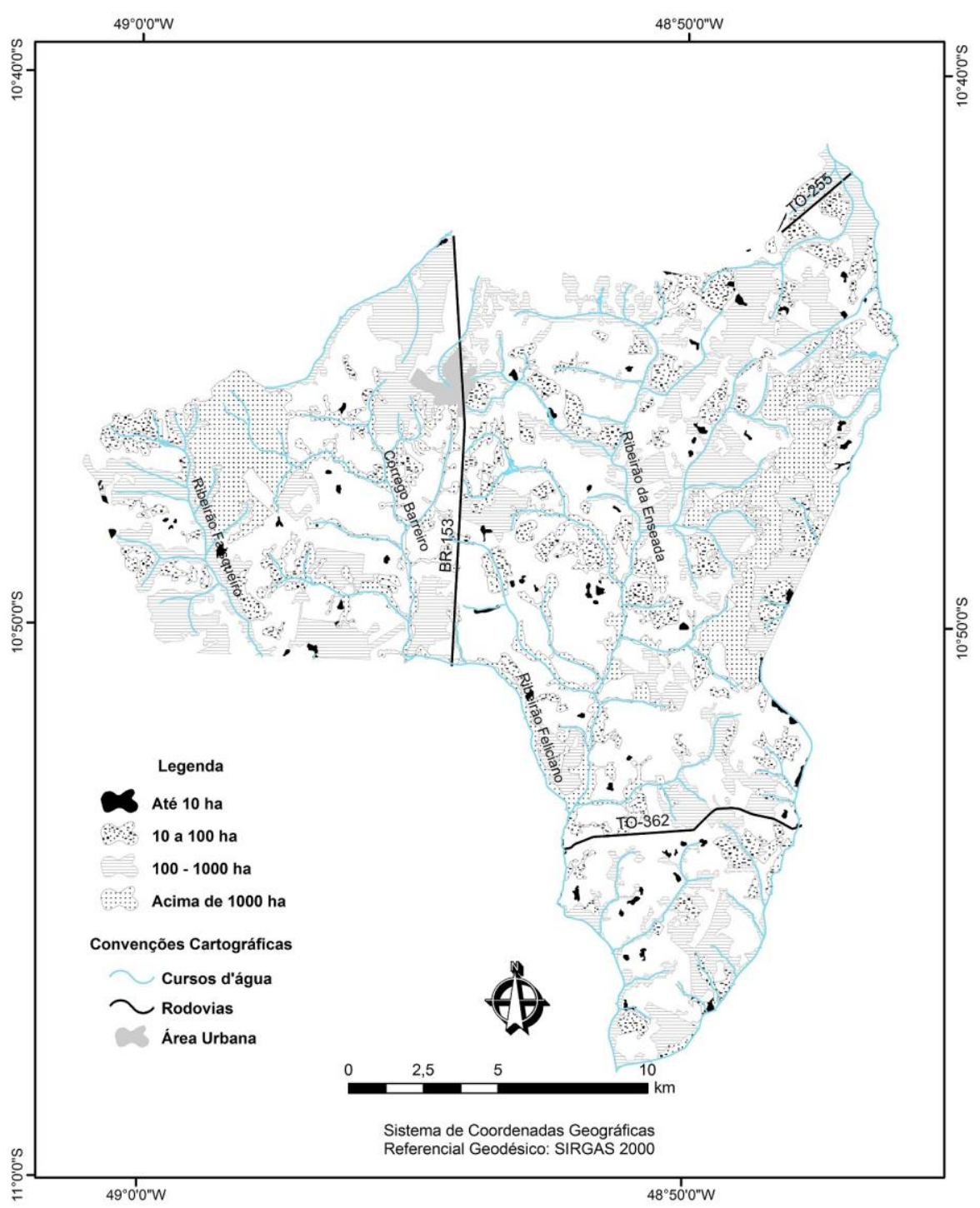

\subsubsection{Fragmentos com até 10 ha}

Os fragmentos com até 10 ha possuem pouca representatividade em área, além de ter $18 \%$ de área interior (62,57 ha), valor baixo e não indicativo de qualidade ambiental. Todavia, Pereira et al. (2012), afirma que os fragmentos com área menor que 10 ha são importantes e devem ser conservados, pois auxiliam na conexão entre os fragmentos maiores. 


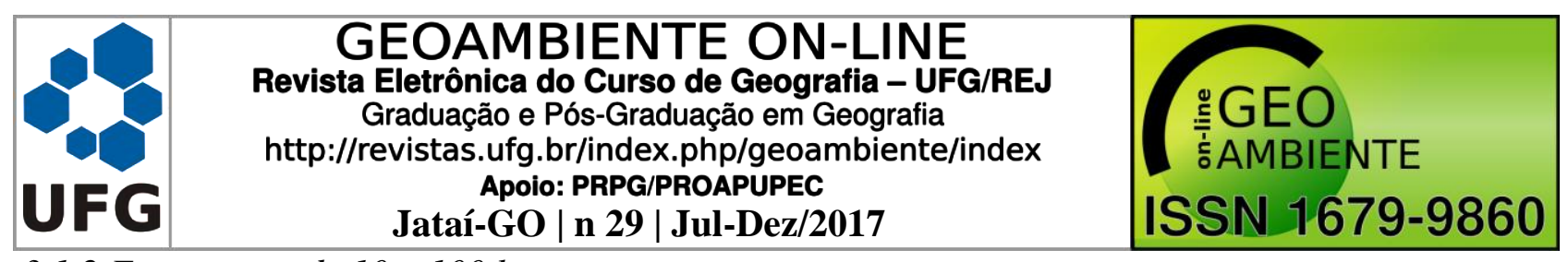

3.1.2 Fragmentos de 10 a 100 ha

Nesta classe de fragmentos (Tabela 4) foram obtidos 120 fragmentos pertencentes a: Floresta Estacional Semidecidual Aluvial, Savana Arborizada, Savana Arborizada/Floresta Estacional Semidecidual Submontana e, Savana Parque. A média de tamanho dos fragmentos é de 35,12 ha e a área interior é de $51,14 \%$ é (2.156,03 ha).

Tabela 4. Fragmentos maiores que 10 ha e menores que 100 ha.

\begin{tabular}{cccccc}
\hline Classes & $\begin{array}{c}\text { Área total da } \\
\text { vegetação (ha) }\end{array}$ & $\begin{array}{c}\text { Número de } \\
\text { fragmentos } \\
\text { (adimensional) }\end{array}$ & $\begin{array}{c}\text { Total de } \\
\text { bordas (m) }\end{array}$ & $\begin{array}{c}\text { Dimensão fractal do } \\
\text { fragmento médio } \\
\text { (adimensional) }\end{array}$ & Área interior (ha) \\
\hline 1 & $1.048,38$ & 27 & $143.840,59$ & 1,34 & 421,56 \\
2 & $3.079,17$ & 88 & $306.205,14$ & 1,28 & $1.718,84$ \\
3 & 16,43 & 1 & $2.787,62$ & 1,32 & 4,28 \\
4 & 71,52 & 4 & $10.094,88$ & 1,28 & 26,18 \\
\hline
\end{tabular}

As classes 1 (Floresta Estacional Semidecidual Aluvial), 2 (Savana Arborizada), 3 (Savana

Arborizada/Floresta Estacional Semidecidual Submontana), 4 (Savana Parque).

$\mathrm{Na}$ de Floresta Estacional Semidecidual Aluvial, foram obtidos 27 fragmentos de tamanho médio 38,82 ha, com tamanho de borda de 143.840,59 m, o tamanho médio destas bordas é de 532,74 m, e a dimensão fractal média 1,35. A área total ocupada pelos fragmentos desta classe é 1.048,38 ha, onde 40,2\% (421,56 ha) é ocupada por área de interior, e 58,8\% da área em ambiente de bordas. Como resultado da análise, a área interior para esta classe é de 421,56 ha correspondente a 77 fragmentos, nisto, observa-se que cada área interior possui pouco mais 5 ha, que segundo Metzger (1997), é insuficiente para manter a sustentabilidade de algumas espécies e a integridade de sua estrutura natural, e que para fragmentos de floresta, a área mínima capaz seria 25 ha.

Na Savana Arborizada são encontrados 88 fragmentos com área total de 1.048,38 ha, tamanho médio de aproximadamente 35 ha, e bordas de 306.205,14 m. O tamanho médio dos fragmentos alcança os 3.479,60 m. A dimensão fractal dessa classe de vegetação é de 1,28. Barros (2012), afirma que a dimensão fractal média representa o nível de irregularidade de um objeto, o valor aqui encontrado indica que os fragmentos possuem perímetros simples, de baixa irregularidade. Os resultados da análise mostram que a área interior para essa classe é de 1.718,84 ha, correspondendo a 137 fragmentos com tamanho médio de 12,5 ha. Este 


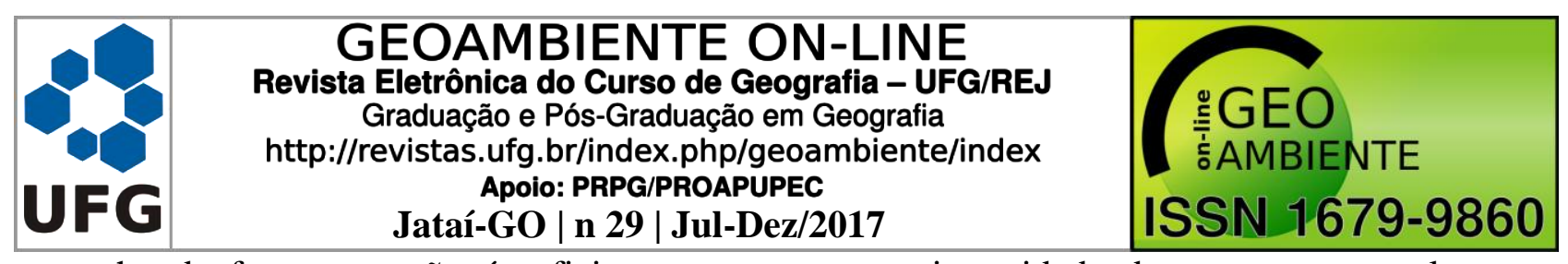

tamanho de fragmento não é suficiente para manter a integridade da estrutura natural e sustentabilidade de algumas espécies (METZGER, 1997).

Na Savana Arborizada/Floresta Estacional Semidecidual Submontana foi encontrado apenas um fragmento como tamanho de 16,43 ha, com borda de 2.787,62 m, e dimensão fractal média de 1,32, possuindo forma regular. $O$ fragmento perde $74 \%$ em bordas, lhe restando $26 \%$ de área interior (4,28 ha).

A Savana Parque possui quatro fragmentos com área total de 71,52 ha, as bordas destes fragmentos totalizam 10.094,88 m, sendo a média de bordas de $2.523,72 \mathrm{~m}$, e a dimensão fractal de 1,28 . Isto indica que os fragmentos são bem regulares e com perímetros simples. Com análises, as áreas de interior para essa classe são de 26,18 ha, correspondendo a sete fragmentos com tamanho médio de 10,2 ha, insuficientes para integridade da estrutura natural.

\subsubsection{Fragmentos de 100 a 1000 hectares}

Nesta classe de fragmentos foram obtidos 42 de fragmentos pertencentes às classes descritas anteriormente, totalizando 9.120,38 hectares de vegetação natural destes, 58\% (5.265,16 ha) é composta por ambientes de borda.

Na Floresta Estacional Semidecidual são encontrados 16 fragmentos com área total de 3.825,27 ha, o tamanho médio dos fragmentos é 239,07 ha, com 504.551,59 m de bordas e a dimensão fractal média é 1,41 (Tabela 5). As áreas de interior analisadas têm tamanho 1.598,02 ha, de 273 fragmentos com tamanho médio de 5,85 ha, ainda insuficientes para estrutura natural. Os fragmentos desta classe possuem mais complexidade nas bordas, sendo mais expostos a efeitos de borda. Mendes e Silva (2008), ratificam esta afirmativa uma vez que para eles uma pequena mata estando cercada por áreas abertas, traz uma série de alterações microclimáticas modificando a abundância e composição de espécies da margem de um fragmento.

$\mathrm{Na}$ Savana Arborizada foram encontrados 23 fragmentos de área total 4.246,63 ha, o tamanho médio destes é 184,63 ha, com bordas de 263.693,56 m, sendo a média de tamanho destas bordas para cada fragmento $11.464,94 \mathrm{~m}$. A dimensão fractal desta classe tem como média 1,29 (Tabela 5). Este valor baixo da dimensão fractal médio, aponta que eles apresentam maior regularidade e simplicidade em sua forma. A área de interior tem 43 fragmentos com área total de 2.996,12 ha, com tamanho médio 69,7 ha. Eles estão bem 


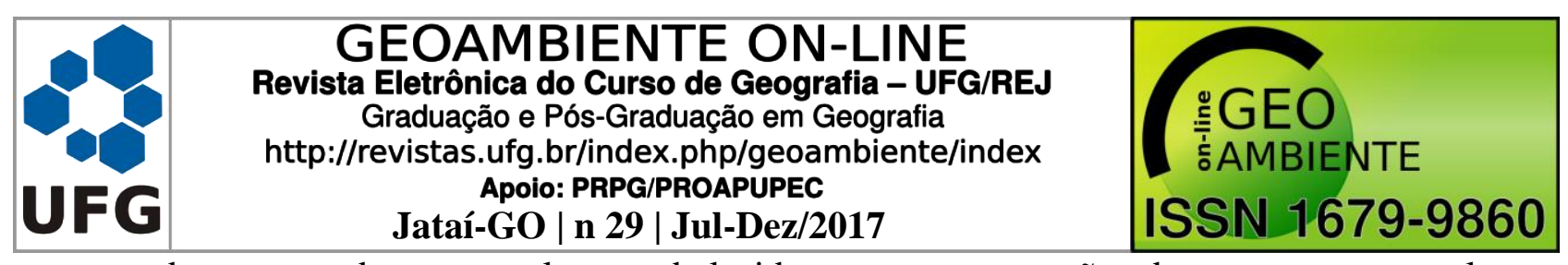

conservados e atendem ao valor estabelecido para conservação da estrutura natural (METZGER, 1997).

Tabela 5. Fragmentos maiores que 100 ha e menores que 1000 ha.

\begin{tabular}{cccccc}
\hline Classes & $\begin{array}{c}\text { Área total da } \\
\text { vegetação (ha) }\end{array}$ & $\begin{array}{c}\text { Número de } \\
\text { fragmentos } \\
\text { (adimensional) }\end{array}$ & $\begin{array}{c}\text { Total de } \\
\text { bordas (m) }\end{array}$ & $\begin{array}{c}\text { Dimensão fractal do } \\
\text { fragmento médio } \\
\text { (adimensional) }\end{array}$ & $\begin{array}{c}\text { Área interior } \\
\text { (ha) }\end{array}$ \\
\hline 1 & $3.825,27$ & 16 & $504.551,59$ & 1,41 & $1.598,02$ \\
2 & $4.246,63$ & 23 & $263.693,56$ & 1,29 & $2.996,12$ \\
3 & 308,57 & 1 & $35.518,36$ & 1,40 & 143,00 \\
4 & 740,31 & 2 & $45.310,06$ & 1,32 & 528,00 \\
\hline \multicolumn{4}{l}{ As classes } & (Floresta Estacional Semidecidual Aluvial), 2 (Savana Arborizada), 3 (Savana
\end{tabular}

Arborizada/Floresta Estacional Semidecidual Submontana), 4 (Savana Parque).

O Encrave Savana Arborizada/Floresta Estacional Semidecidual Submontana possui apenas um fragmento com o tamanho 308,57 ha, com borda de 35.518,36 m e dimensão fractal média de 1,40 (Tabela 5). Este fragmento tem mais complexidade na borda. A área interior é de 143 ha com 16 fragmentos de tamanho médio de 8,94 ha cada, sendo classificados ainda como insuficientes para integridade de sua estrutura natural.

$\mathrm{Na}$ Savana Parque, foram encontrados dois fragmentos com área total 740,31 ha, 45.310,06 m de bordas, e dimensão fractal média de 1,32 (Tabela 5). Este valor aponta que a estrutura destes fragmentos é simples e com baixo grau de irregularidade. As áreas de interior têm tamanho de 528,00 ha, com seis fragmentos, onde a média de tamanho dos fragmentos é de 88 ha. O tamanho é suficiente para manutenção de espécies e integridade estrutural dos fragmentos (METZGER, 1997).

\subsubsection{Fragmentos acima de 1000 hectares}

Nesta classe de tamanho de fragmentos de vegetação natural foram encontrados três fragmentos de Floresta Estacional Semidecidual Aluvial e Savana Arborizada com tamanho médio $1.723,34$ ha e área interior de 58\% (3013,68 ha).

$\mathrm{Na}$ Floresta Estacional Semidecidual Aluvial foi encontrado apenas um fragmento com tamanho $2.375,74$ ha e com bordas $325.044,13 \mathrm{~m}$, e a dimensão fractal média é de 1,49 (Tabela 6). Valor alto para a dimensão fractal média que aponta que o fragmento tem forma complexa e irregular. O fragmento tem 39\% de área interior (916,63 ha), os outros $61 \%$ são 


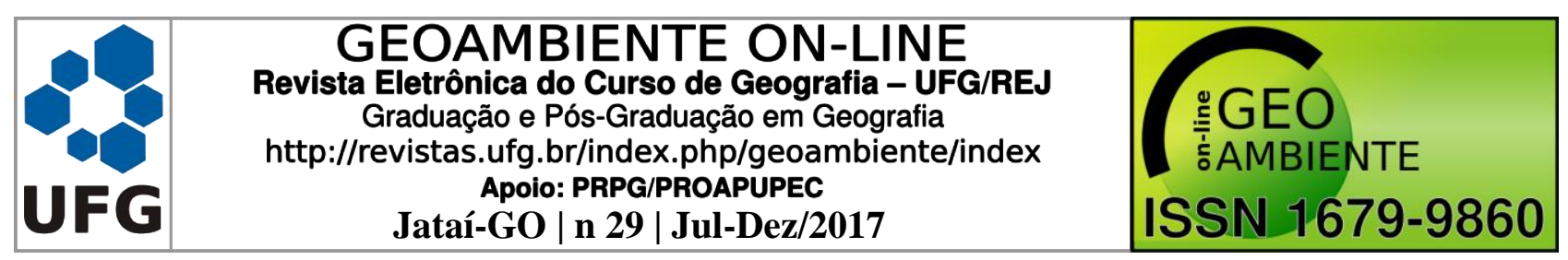

ambientes de borda. Isto mostra o efeito da fragmentação na Floresta Estacional Semidecidual

Aluvial. Para os 178 fragmentos de área interior, o tamanho médio de 5,15 hectares de área interior para cada fragmento, sendo área insuficiente para manutenção e desenvolvimento de espécies. O fragmento desta classe tem tamanho suficientemente grande para manutenção e desenvolvimento de espécies, porém devido ao reduzido número de área interior, acaba por não ser considerado com relevante para este papel. Todavia, a Floresta Estacional Semidecidual Aluvial, uma formação ripária, tem papel preponderante para a conexão entre fragmentos e constitui corredores ecológicos naturais que permitem o fluxo gênico de espécies.

Na Savana Arborizada foram encontrados dois fragmentos com 2.794,28 ha de área total, a média de tamanho destes é 1397,14 ha e as bordas tem 144.955,15 m, cuja média das bordas chega aos 72.477,58 m. Os fragmentos têm dimensão fractal média é de 1,35, regular e simples (Tabela 6). As áreas de interior somam 75\% (2.097,05 ha) da área total, com 16 fragmentos de área interior, sendo a média dos fragmentos de 131,06 ha. Este tamanho de área é suficiente para manutenção e desenvolvimento de espécies. Os fragmentos com área grandes têm grande importância para manutenção e qualidade ambiental em termos da conservação da biodiversidade da fauna e flora (PEREIRA et. al., 2012).

Tabela 6. Fragmentos acima de 1000 hectares.

\begin{tabular}{cccccc}
\hline Classes & $\begin{array}{c}\text { Área total da } \\
\text { vegetação (ha) }\end{array}$ & $\begin{array}{c}\text { Número de } \\
\text { Fragmentos } \\
\text { (adimensional) }\end{array}$ & $\begin{array}{c}\text { Total de } \\
\text { bordas (m) }\end{array}$ & $\begin{array}{c}\text { Dimensão fractal do } \\
\text { fragmento médio } \\
\text { (adimensional) }\end{array}$ & $\begin{array}{c}\text { Área } \\
\text { interior } \\
\text { (ha) }\end{array}$ \\
\hline 1 & $2.375,74$ & 1 & $325.044,13$ & 1,49 & 916,63 \\
2 & $2.794,28$ & 2 & $144.955,15$ & 1,35 & 2097,05 \\
\hline
\end{tabular}

As classes 1 (Floresta Estacional Semidecidual Aluvial), 2 (Savana Arborizada).

\subsection{Proposta de corredor ecológico}

A proposta de corredor ecológico (Figura 4), como uma medida de reparação de pressão nas áreas em que os fragmentos já perderam a qualidade ambiental e evitar que os maiores fragmentos (parte leste da Bacia Hidrográfica do Ribeirão Enseada, nos contrafortes da Serra das Cordilheiras) reduzam suas áreas ou ainda percam a sua qualidade ambiental, consequentemente o fluxo gênico da flora e da fauna. Esta medida poderá ainda promover a recolonização das áreas degradadas, conservando assim a biodiversidade da paisagem e a sucessão ambiental da região. 


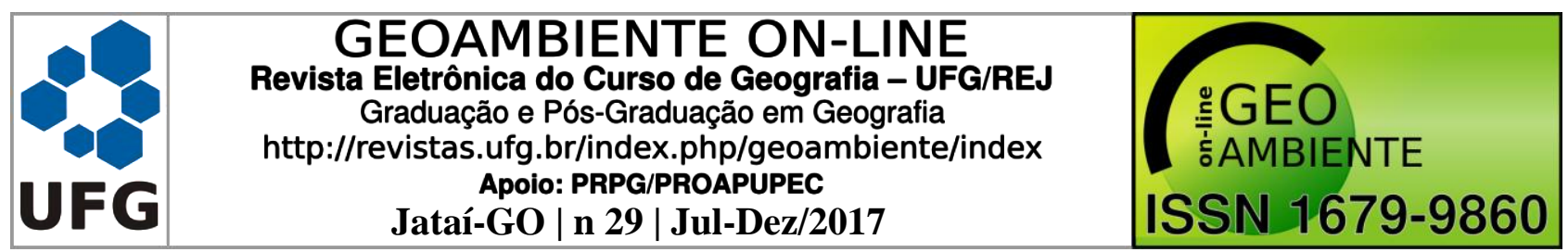

Figura 4. Mapa com proposta de corredor ecológico

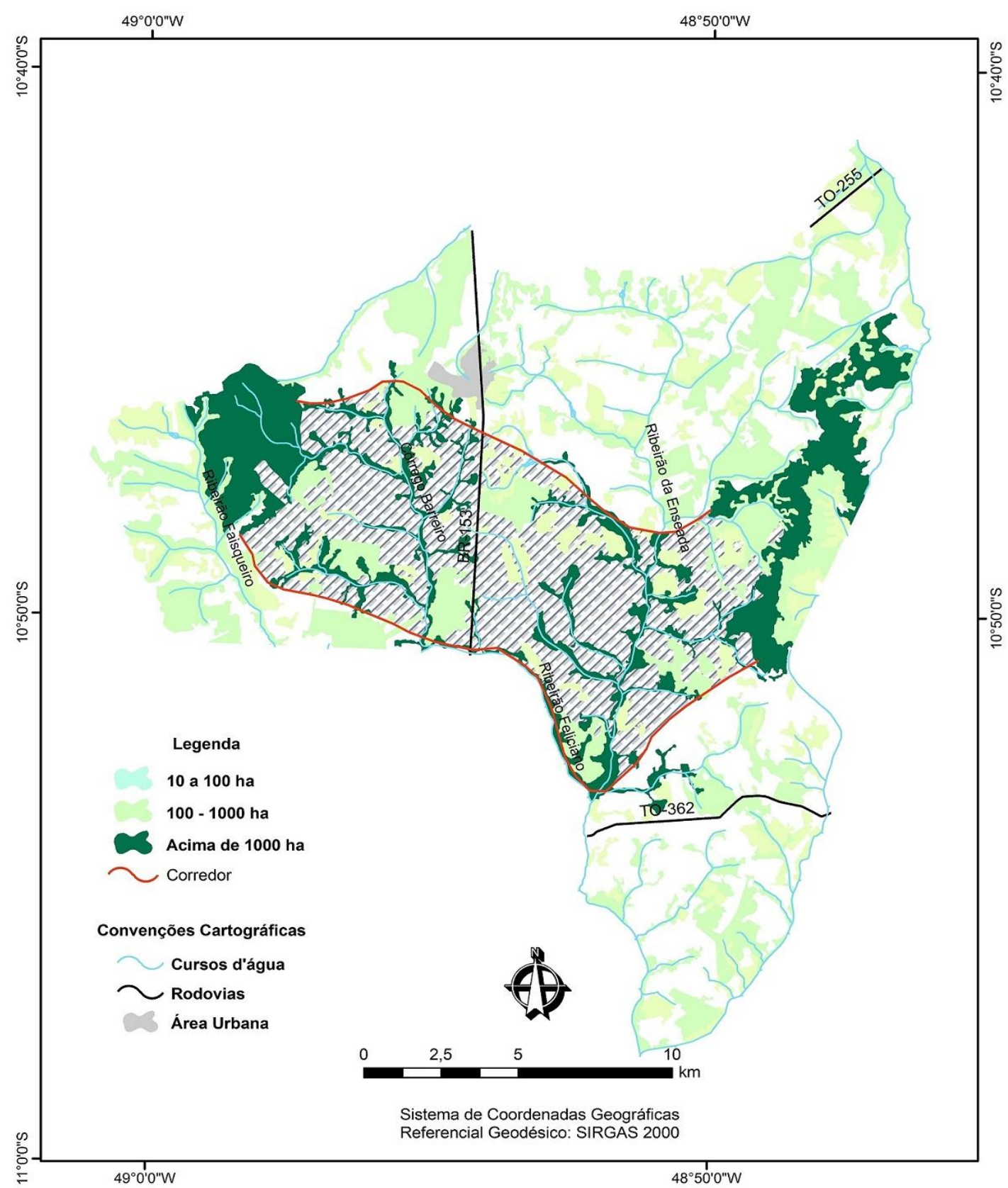

\section{CONSIDERAÇÕES FINAIS}

- A Floresta Estacional Semidecidual Aluvial e encrave Savana Arborizada/Floresta Estacional Semidecidual Submontana apresentaram maior grau de fragmentação estando prejudicadas em relação à qualidade ambiental, chegando a ter mais que $50 \%$ da vegetação natural como ambiente de borda. Nesta ótica elas não deveriam fazer 


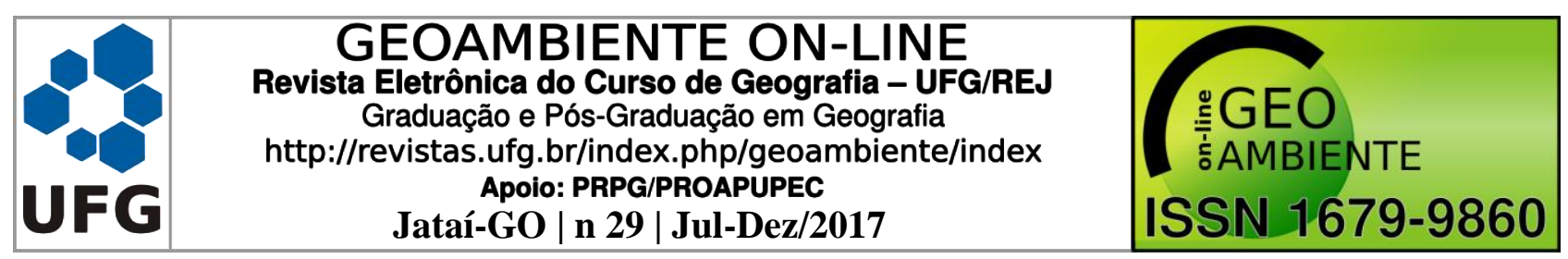

parte de programa de conservação, todavia pela posição estratégica que ocupam, a Floresta Estacional Semidecidual Aluvial acaba sendo fundamental para estabelecer a conectividades entre diferentes tipologias vegetais e favorecer a dispersão das espécies.

- A Savana Parque entre os tamanhos de 100 a 1000 hectares possui bom grau de conservação de áreas de interior, e apresenta regularidade em seus fragmentos.

- A Savana Arborizada que apresenta maior extensão entre as classes de tamanhos, também expressa maior regularidade em suas formas e ainda um bom grau de conservação de áreas interior. Os dois fragmentos de grande extensão em lados opostos do Ribeirão Enseada, são os mais indicados para estudos posteriores de conservação ambiental e as suas conectividades podem ser estabelecidas por meio de fragmentos de Floresta Estacional Semidecidual.

\section{REFERÊNCIAS}

ANDRADE, T. G. Identificação de áreas potenciais para recarga de aqüíferos no Município de Fátima, Estado do Tocantins. 2016. Trabalho de Conclusão de Curso. (Graduação em Engenharia Ambiental) - Fundação Universidade Federal do Tocantins. Palmas, TO. 2016.

BARROS, M. P. Dimensão fractal e ilhas de calor urbanas: uma abordagem sistêmica sobre as implicações entre a fragmentação das áreas verdes e o ambiente térmico do espaço urbano. Tese (Doutorado em Física Ambiental) - Universidade Federal do Mato Grosso. Cuiabá - MT. 2012.

BOHRER, C. B. A. Vegetação, paisagem e o planejamento do uso da terra. GEOgraphia, Rio de Janeiro. Ano II, no 4, p. 103 - 120, 2000.

BORGES, L. F. R; SCOLFORO, J. R.; OLIVEIRA, A. D.; MELlO, J. M.; ACERBI JUNIOR, F. W.; FREITAS, G. D. Inventário de fragmentos florestais nativos e propostas para seu manejo e o da paisagem. Cerne, Lavras, v. 10, n. 1, p. 22-38, jan./jun. 2004.

CRUZ, C.; MADUREIRA, H.; MARQUES, J. Análise espacial e estudo da fragmentação da Paisagem da Aboboreira. Revista de Geografia e Ordenamento do Território (GOT), n. ${ }^{\circ} 4$ (dezembro). Centro de Estudos de Geografia e Ordenamento do Território, p. 57-82., 2013.

CULlEN JR., L.; RUDRAN R.; PADUA, C. V. Métodos de estudos em biologia da conservação e manejo da vida silvestre. Curitiba: UFPR, 2006. EMBRAPA -2016. Disponível 


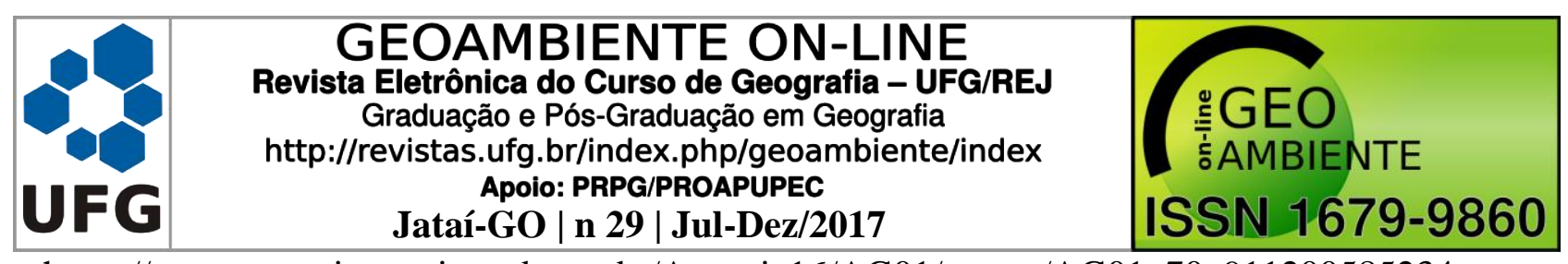

$<$ https://www.agencia.cnptia.embrapa.br/Agencia16/AG01/arvore/AG01_70_911200585234. html>. Acesso em 27 jan 2016.

FARINACI, J. S.; BATISTELLA, M. Variação na cobertura nativa em São Paulo: Um panorama do conhecimento atual. Revista Árvore, Viçosa-MG, v.36, n.4, p.695-705, 2012.

IBGE 2014 - Instituto Brasileiro de Geografia e Estatística. Disponível em: <http://www.ibge.gov.br/>. Acesso em 12 dez 2015.

LAURENCE, W. F. Edge effects in tropical Forest fragments - application of a model for the design of nature-reserves. Biological Conservation, v. 2, n. 52, p. 205-219.1991.

LEAL, J. V.; TODT, J.; THUM, A. B. O uso de SIG para o monitoramento de áreas degradadas - estudo de caso: App do Arroio Gil, Triunfo - RS. Revista Brasileira de Cartografia, Rio de Janeiro, nº 65/5, p. 967 - 983, 2013.

MCGARIGAL; K.; B. J. MARKS. FRAGSTATS: Spatial pattern analysis program for quantifying landscape structure. Corvallis: Oregon State University, 1994.

MCGARIGAL, K.; MARKS, B. J. Fragstats: Spatial pattern analysis program for quantify in glandscape structure. Reference manual. For. Sci. Dep. Oregon State University. Corvallis Oregon Append. 1995.

MENDES, J. D.; SILVA, N. M. Avaliação do efeito de borda em fragmentos de cerrado por meio de métricas de paisagem, no Parque Nacional de Chapada dos Guimarães, Mato Grosso, Brasil. IX Simpósio Nacional Cerrado. 2008. Anais... Parlamundi, Brasília, DF. 2008.

METZGER, J. P. Relationships between landscape structure and tree species diversity in tropical forets of South-East Brazil. Landscape and Urban Planning. n 37, p.29-35. 1997.

MISSIO, E.; TONIAL, T. M.; SANTOS, J. E.; HENKE-OLIVEIRA, C.; ZANG, N.; PIRES, J. S. R. Análise ambiental e dinâmica do uso da terra de unidades da paisagem para o manejo de bacias hidrográficas. In: SANTOS, J. E.; CAVALHEIRO, F.; PIRES, J. S. R. Faces da polissemia da paisagem: ecologia, planejamento e percepção. 1 ed. São Carlos, p. 211-232, 2004.

MONTEIRO, C. B.; MARTINS, A. K. E. Uso de Geotecnologia para Análise do Cerrado na Paisagem da sub-bacia do ribeirão Taquaruçu-Grande, Palmas-TO. In: Simpósio Brasileiro de Sensoriamento Remoto, 16. (SBSR)., 2013, Foz do Iguaçu. Anais... São José dos Campos: INPE, 2013.

OLIVEIRA, L.T. Caracterização da fragmentação florestal para produção de sementes no entorno capixaba do Parque Nacional do Caparaó. 2011. Monografia apresentada ao 


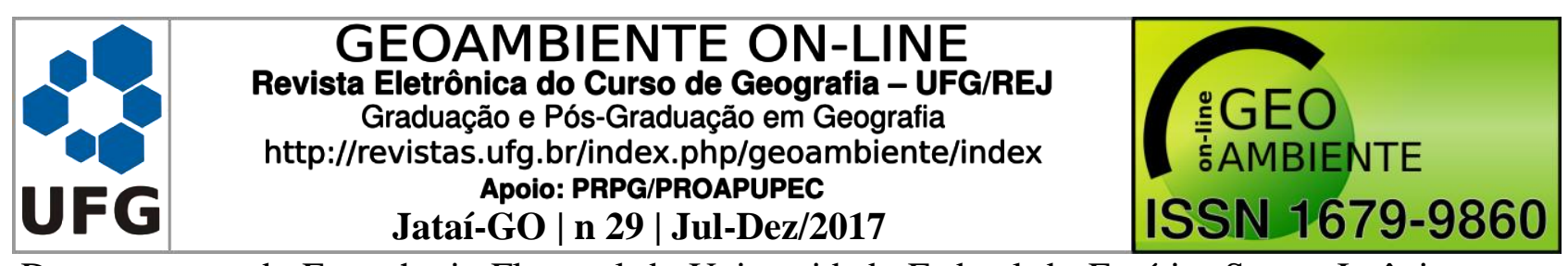

Departamento de Engenharia Florestal da Universidade Federal do Espírito Santo. Jerônimo Monteiro, ES. 2011.

PEREIRA, J. L. G.; BATISTA, G. T.; THALÊS, M. C.; ROBERTS, D. A.; VENTURIERI, A. V. Métricas da paisagem na caracterização da evolução da ocupação da Amazônia. Geografia, v. 26, n. 1, p. 59-90, abr. 2001.

PEREIRA, B. W.; JESUIN, S. A.; MACIEL, M. N.; OLIVEIRA, F. A.; CREÃO, L. G. C. Fragmentação da vegetação arbórea na bacia hidrográfica do Rio Apeú, Nordeste do Estado do Pará. Revista de Ciências Agrárias. v. 55, n. 4, p. 297-305, out./dez. 2012.

REMPEL, C. A ecologia de paisagens e suas ferramentas podem aprimorar o zoneamento ambiental? O caso da região política do vale do Itaguari. 2009. Tese de doutorado. Universidade Federal do Rio Grande do Sul, Porto Alegre, RS.

SANTOS, A. A.; MACHADO, M. M. M. Análise da fragmentação da paisagem do parque nacional da Serra da Canastra e de sua zona de amortecimento - MG. Revista Raega,v.33, p.75-93, 2015.

SARCINELLI, T.S. Representatividade ambiental e fragmentação florestal em áreas dominadas por plantios homogêneos: uma proposta para o arranjo espacial de fragmentos florestais. 2006. Dissertação (Mestrado em solos e nutrição de plantas). Viçosa: Universidade Federal de Viçosa, UFV, 2006.

SEPLAN - Secretaria do Planejamento e da Modernização Pública. Atlas do Tocantins: Subsídios ao planejamento da gestão territorial. Palmas, TO. 6 ed. 80 p. 2012.

SEPLAN - Secretariado Planejamento e da Modernização da Gestão Pública. Mapeamento das regiões fitoecológicas e inventário florestal do Estado do Tocantins. $1^{\text {a }}$ Ed. 2013.

SILVA, G. B. S.; MELlO, A. Y. I.; STEINKE, V. A. Unidades de conservação do bioma cerrado: desafios e oportunidades para conservação no Mato Grosso. Revista de Geografia, Rio Claro, v. 37, n. 3, p. 541-554, 2012.

VIANA, V. M.; PINHEIRO, L. A. F. V. Conservação da biodiversidade em fragmentos florestais. Série Técnica IPEF, v. 12, n. 32, p.25-42, 1998.

VOLOTÃO, C. F. S. Trabalho de análise espacial: métricas do Fragstats. São José dos Campos: INPE. p.45, 1998. 